\title{
Agents to Maintain Tooth Integrity: An Equilibrium between Remineralization and Demineralization - A Review
}

\author{
Jyotika Saini, Anil Gupta, Ankit Srivastava, Shikha Kataria
}

Department of Pedodontics and Preventive Dentistry, Faculty of Dental Sciences, SGT University, Budhera, Haryana, India

\begin{abstract}
Changing concepts of dentistry have the aim to manage initial caries lesions with the help of remineralizing agents in an attempt to arrest or revert the disease progression by the process of depositing calcium and phosphate ions in enamel and hence, gaining net mineral loss. Concentrating mainly on prevention and early intervention of caries, minimally invasive dentistry's first basic principle is the remineralization of early carious lesions. The purpose of this article is to review current knowledge and technologies for tooth remineralization and their applications in clinical practices.
\end{abstract}

Key words: Remineralization, demineralization, white spot lesions, tooth integrity, critical pH

\section{INTRODUCTION}

Remineralization is a natural repair process for non-cavitated lesions with the help of calcium and phosphate ions along with fluoride to remineralize the lesion surface after demineralization. ${ }^{[1]}$ Demineralization is the loss of calcified material from the structure of the tooth. The dynamic balance between demineralization and remineralization determines the occurrence of dental caries. Dental caries is the most common microbial disease of dental hard tissue which causes loss of tooth surface due to acids produced by bacteria in the dental biofilm..$^{[2-6]}$ Saliva plays an important role in the natural process of remineralization of tooth as saliva is rich in calcium and phosphate ions. Critical $\mathrm{pH}$ is the $\mathrm{pH}$ at which saliva is no longer saturated with respect to calcium and phosphate ions, thereby permitting hydroxyapatite to dissolve. It is unlikely that

\begin{tabular}{|l|l|}
\hline \multicolumn{2}{|c|}{ Access this article online } \\
\hline \multicolumn{1}{|c|}{ Publisher } & \multicolumn{1}{|l|}{ Website: } \\
& www.ijdms.in \\
DOI: 10.30954/IJDMS.1.2019.4
\end{tabular}

demineralization would occur above 5.5 and this value has often been accepted as being "safe for the teeth." ${ }^{[7-9]}$ As the $\mathrm{pH}$ is lowered, acids diffuse rapidly from underlying enamel or dentin. If the demineralization phase continues for a long period of time, excessive loss of minerals results which leads to loss of enamel structure and hence, cavitation of tooth structure occur. Therefore, nowadays focus on prevention for an extension to the detection of early stages of carious lesion and use of non-invasive treatment of initial lesions, i.e., remineralization at early stages of lesion area to prevent cavitation. ${ }^{[10-12]}$

\section{Classification of Remineralizing Agents}

- Fluoridated agents

- Non fluoridated agents.

\section{Based on Calcium Phosphate Remineralization}
a. Casein phosphor-peptide-amorphous calcium phosphate (CPP-ACP)
b. ACP
c. Bioactive glass materials
d. Tri-calcium phosphate (TCP)
e. Dicalcium phosphate dehydrate (DCPD)

\section{Address for Correspondence:}

Dr Jyotika Saini, Post Graduate, Department of Pedodontics and Preventive Dentistry, Faculty of Dental Sciences, SGT

University, Budhera, Gurugram, Haryana - 122505, India. E-mail: jyoticamj211@gmail.com

Submission: 06 Jun 2018; Revision: 06 Jul 2018; Acceptance: 21 Jul 2018 
f. Nano-hydroxyapatite (nHA)

g. Pronamel

h. Calcium carbonate carrier (sensistat)

i. Cavistat

j. Trimetaphosphate ions (TMP)

k. Biomimetically modified mineral trioxide aggregate.

- Sugar substitute
a. Xylitol
b. Sorbitol
c. Isomalt.

- Ozone

- Natural agents.

a. Grape seed extract (GSE)

b. Ginger extract along with Rosenbery and Honey.

- Self-assembling peptides

- Remineralization using iontophoresis

- Remineralization using lasers.

\section{Fluoridated Agents}

Fluoride is known to prevent Dental Caries since decades. It protects the dental enamel from caries by reducing enamel dissolution and enhancing enamel remineralization process. Fluoride reduces the acid solubility by inducing fluorapatite or fluoridated hydroxyapatite formation through reaction with hydroxyapatite directly. In 1945, Bibby published his findings on Sodium Fluoride (NaF) incorporated into toothpastes. There is a wide range of fluoride compounds and agents available to the public and health-care professionals. ${ }^{[13]}$ Various fluoridated agents which enhance tooth resistance to demineralization or remineralize the initial caries lesions are: Fluoride-releasing restorative material.

Mohammed et al., in 2015, stated the "burst effect" associated with the high release of fluoride from dental materials.

\section{Silicate Cements}

The first fluoride releasing tooth colored restorative material was silicate cement. Fluoride incorporated into silicate powder can be as high as 1,30,000 ppm. D. Diony Thessaloniki, Greece in 2014 have done the study to show the ability of restorative material to act as a fluoride reservoir mainly dependent on the type and permeability of filling material, on the frequency of fluoride exposure, and the kind and concentration of the fluorinating agent. ${ }^{[14]}$

Commercially available as: Silicate cement ADA SP NO. 96.

\section{Glass Ionomer Cements}

The outer surface of the restoration is exposed to oral fluids and plaque with which it has a continuous exchange of ion. While wear resistance of the restoration is low at placement, it steadily increases with time and ion uptake. At placement, there is a significant release of ions from the cement which combines with similar ions from the dentinal fluid to promote remineralization. Mount in 2002 have proved that glass ionomer cements are valuable for initial carious lesions and caries control in a high caries risk patients. ${ }^{[15]}$

Commercially available as: GC Gold label, GC Fuji, Medicept Xtracem 3M ESPE Rely ${ }^{\mathrm{TM}}$.

\section{Resin Composites}

Van Meer. and Perdigao et al. stated in 2013 stated that fluoride-releasing composite resin has better mechanical properties, no inherent adhesive properties, greater thermal expansion coefficient, and wear resistance compare to other materials. However, they also have the smallest amount of fluoride release and provide almost no long-term fluoride release through recharge.

Commercially available as: Nexus ${ }^{\mathrm{TM}}$ RMGI.

\section{Compomers}

Compomer is a combination of the word "comp" for composite "omer" for ionomer. It can be used to increase remineralization at initial white spot lesions. Kang., Kakem et al. in 2002 had done a study to compare the amount of fluoride release and remineralizing effect of compomer with those of glass ionomer cement and composite resin and they have concluded that the highest degree of remineralization was observed in glass ionomer group followed by the compomer group.

Commercially available as: Dyract Xtra, Uno Dent Compomer LC.

\section{CPP-ACP}

The concept of using CPP-ACP as an remineralizing agent was introduced in 1998 by Professor Eric Reynolds, University of Melbourne, Australia, and casein for caries prevention was given in early 1980s. ACP technology was introduced in the 1990s by Dr. Ming S. Tung. CPP bound ACP are the reservoir of calcium and phosphate ions including the neutral ion pair $\mathrm{CaHPO}_{4}$. Under acidic condition, CPP-bound ACP will buffer plaque $\mathrm{pH}$ and dissociate to calcium and phosphate ions including $\mathrm{CaHPO}_{4}$. With increase in plaque calcium and phosphate, the $\mathrm{pH}$ of saliva remains neutral thereby, preventing demineralization. Shirahatti et al. (2015) demonstrated the use of non-fluoridated dentifrice and also the use of paste incorporated with CPP-ACP can reduce the progression in depths of enamel lesions when applied to early lesions. ${ }^{[16]}$

CPP-ACP commercially available as: MI Varnish- Recaldent ${ }^{\circledR}$ GC Corporation Tokyo, Japan, GC Tri Plaque ID Gel ${ }^{\mathrm{TM}}$, GC Tooth Mousse Plus ${ }^{\mathrm{TM}}$, GC Recaldent GC Sugar-free chewing gums. 


\section{Bioactive Glass (Novamin)}

Bioactive glass was invented by Dr. Larry Hench in 1960s. Novamin adheres to the exposed dentin surface and forms a mineralized layer that is mechanically strong and resistant to acid. Gjorgievska and Nicholson (2016) investigated the enamel remineralization potential of two toothpastes, one of which was based on Recaldent ${ }^{\mathrm{TM}}$ (CPP-ACP) and the other on Novamin ${ }^{\mathrm{R}}$ (calcium-sodium phosphor silicates) and concluded the equal effect of remineralization. ${ }^{[17]}$ NovaMin ${ }^{\circledR}$ - A trade name for bioactive glass.

\section{TCP}

TCP enhances the levels of calcium in plaque and saliva but the level of TCP has to be kept very low, in order of $<1 \%$ as they form calcium-phosphate complexes which inhibit remineralization by lowering the levels of bioavailable calcium and fluoride. Karlinsey et al., 2009, have conducted a study and concluded the effect of Tri-calcium phosphate to support fluoridebased remineralization and deliver functional forms of bioavailable calcium and phosphate that help to incorporate fluoride deeper into the enamel. ${ }^{[18]}$

Commercially available as: $3 \mathrm{M}$ Espe Clin $\mathrm{Pro}^{\mathrm{TM}}$, Clinpro 5000 toothpaste.

\section{DCPD}

DCPD in dentifrice increases the levels of free calcium ions in plaque fluid, and these remain elevated for up to $12 \mathrm{~h}$ after brushing when compared to conventional silica dentifrice. It also enhances calcium into enamel, and increased levels are detected into plaque up to $18 \mathrm{~h}$. An intra-oral remineralization-demineralization study was performed to evaluate NaF/DCPD's ability to promote remineralization in comparison to 3 silica-based dentifrices containing 0,250 , and $1100 \mathrm{ppm} \mathrm{F}$ and $\mathrm{NaF}$. A statistical analysis showed that the dual chamber sodium fluoride/ DCPD dentifrice was significantly more effective than the 1100 ppm Sodium Fluoride/Silica dentifrice at promoting remineralization. ${ }^{[19]}$

\section{Nanohydroxyapatite (Reminpro)}

A concentration of $10 \%$ nHA is considered to be optimal for remineralization of early enamel caries. Halel Heshmet and Solmez Jaberi, in 2015, had done a study to compare the effect of CPP-ACP, fluoride (MI Paste Plus), and Remin Pro for remineralization and concluded that remineralization was significantly increased in the group with Remin Pro and CPP-ACPF then the fluoride MI paste plus. ${ }^{[20]}$

Commercially available as: REMINPRO (VOCO, Germany).

\section{Pronamel}

Pronamel helps in relieving tooth sensitivity and has a neutral $\mathrm{pH}$ and a low abrasivity. After treatment with the remineralizing solutions followed by Pronamel, both interprismatic and prismatic enamel structures are remineralized. Rees J, Loyn et al. in 2007 had done a study to focus on remineralization and compared Proenamel ${ }^{\mathrm{TM}}$ and GC MI Paste/Tooth Mousse ${ }^{\mathrm{TM}}$ and concluded that both agents have shown significant remineralization effects. ${ }^{[21]}$

\section{Calcium Carbonate Carrier (Sensistat)}

It was developed by Dr. Israel Kleinberg at Stony Brook. As it is alkaline in nature, Sensistat reacts with the calcium and phosphate ions of the dentinal fluid to make the plug chemically attached to the dentinal walls making it more secure. It can also be used to treat early surface demineralization and regress the development of caries that require restoration. Moreau and Sun et al. in 2014 had shown that calcium carbonate nanoparticles were reserved on the collagen-coated surfaces in the model system and then may also be retained on oral surfaces, therefore releasing of calcium ions into oral fluids for remineralization was occurred. ${ }^{[3]}$

\section{Cavistat}

A sugarless mint known as basic mint containing Cavistat ${ }^{\circledR}$ (an arginine bicarbonate calcium carbonate complex) is used as an additive in toothpastes for reducing caries and enhancing remineralization. Ana Maria et al. in 2015 have conducted a study to determine sugarless mint containing CaviStat ${ }^{\circledR}$ is capable of preventing the development of dental caries in the primary molars, and they have concluded that mint confections containing CaviStat are able to inhibit caries onset, caries progression and also promotes remineralization. ${ }^{[1]}$

\section{TMP}

TMP work by making a barrier coating by adsorbing agents to the enamel surface, which are effective in preventing demineralization during acid challenges. TMP diffuse the calcium ions to the inner of enamel which enhances remineralization. ${ }^{[21]}$

\section{Biomimetically Modified Mineral Trioxide Aggregate}

Mineral trioxide aggregate helps in remineralization by incorporating polyacrylic acid and sodium tripolyphosphate as biomimetic analog of matrix proteins. Hydroxyapatite can release calcium and phosphorus continuously, a process required for bone metabolism. In addition, this phenomenon increases the sealing ability of MTA and promotes the regeneration and remineralization of hard tissues. Pratiwi and Meidyawati et al. in 2017 have conducted a study to compare 
the remineralization of deep carious lesion-affected dentine with the removal of some and all the infected dentine after the application of MTA and have concluded that remineralization occurred in both groups after the MTA application. ${ }^{[22]}$

\section{Xylitol}

Trahan in 1992 had demonstrated 2 key factors which were advanced for expected mode of action of xylitol. First, some oral bacteria, like the caries-associated mutans streptococci, are unable to utilize xylitol in their metabolism and thus, fewer acids are formed in the oral biofilm secondly, long-term use of xylitol may ecologically select for mutans streptococci strains with an impaired adhesiveness for tooth surfaces. The use of chewing gum carrying xylitol increases salivary flow rate, helps in remineralization and enhances the protective properties of saliva. This is because the concentration of bicarbonate and phosphate is higher in stimulated saliva, and the resultant increase in plaque $\mathrm{pH}$ and salivary buffering capacity prevents demineralization of tooth surfaces. Ritter and Bader et al. had proved xylitol as a significant reduction in caries incidence and increased tooth remineralization. ${ }^{[23]}$

Xylitol in oral syrups commercially available as: Mematrix Xylitol syrup.

\section{Sorbitol (D-glucitol)}

Firestone et al. in 1982 suggested that Streptococcus mutans have enzymes to degrade sorbitol which makes the fermentation process slow and allows a little $\mathrm{pH}$ to drop of dental plaque. This permits salivary buffers to neutralize acid end products and chewing sorbitol-sweetened gums for 5 min after receiving a sucrose rinse has shown to reduce remineralization. Firestone AR et al. (1982) conducted a 2 years study and concluded that "gum" group exhibited $38.7 \%$ reduction in incremental caries compared with the control group. ${ }^{[24]}$

\section{Isomalt (Palatinit)}

Isomalt is a non-cariogenic sweetener that is widely used as a sugar substitute. It is obtained by dehydrogenation of palatinose. The sweetness of Palatinit is $45 \%$ that of sucrose. Adding isomalt to a demineralizing solution has shown to significantly reduce tooth mineral loss. ${ }^{[24]}$

\section{Ozone}

The word ozone was first introduced by Schonbein in 1840. Ozone $\left(\mathrm{O}_{3}\right)$ is a powerful oxidizing agent which neutralizes acids and effects on cell structures, metabolism of microorganisms. Ozone has immediate direct effect on carious lesion by eliminating the acid producing bacteria and by delaying indirect effect by promoting the remineralization of the lesions. Al-Duboni in 2013 conducted a study to evaluate the efficiency of ozone alone and with a remineralizing solution and concluded that Ozone treatment either alone or combined with a remineralizing solution is effective for remineralization of initial fissure caries lesions. ${ }^{[25]}$

Commercially available as: CurOzone USA Inc. (Ontario, Canada) developed the Heal Ozone, which is now distributed by KaVo Dental (KaVo, Biberach, Germany).

\section{GSE}

GSE is a rich source of proanthocyanidins which strengthen collagen-based tissues by increasing collagen cross-links. GSE decreases the degradation rate of the dentin matrix after bacterial collagenase treatment, indicating an inverse relationship between concentration of GSE and collagen solubilization by enhancing remineralization. Khaddam et al. in 2014 had done a study to evaluate the capacity of a GSE mouth rinse to prevent the degradation of demineralized dentin matrix, and they have concluded that GSE either alone or combined with amine fluoride as in the evaluated mouth rinse limits dentin matrix degradation and enhanced remineralization. ${ }^{[26]}$

\section{Ginger Extract along with Rosenbery and Honey}

Ginger rhizome (Zingiber officinale) is a natural herbal with their antimicrobial activities that are commonly used herbal supplements. The antifungal and antibacterial activity of ginger has been attributed to gingerol and shagelol derived from the ethanolic extracts of ginger. Honey is a supersaturated sugar solution with low water activity that does not support the growth of bacteria. The average $\mathrm{pH}$ value of honey is 3.9 and can show the bacteriostatic effect on pathogens as most thrive at $\mathrm{pH}$ between 4.0 and 4.5 . High remineralization is probably due to antimicrobial properties of ginger which might be the result of high amount of fluoride content $(79 \mathrm{mg} / \mathrm{kg}$ fluoride in $8 \mathrm{mg})$. By the addition of honey, the content of fluoride had decreased to $23.7 \mathrm{mg} / \mathrm{kg}$. Even though $\mathrm{NaF}$ toothpaste had much more fluoride $(1450 \mathrm{mg} / \mathrm{kg})$, it has provided less remineralization than ginger and honey mixture. Al-Duboni G, et al. (2013) compared rosemary methanolic extract $(30 \mathrm{~g} / 100 \mathrm{~mL})$ with chlorhexidine and found that rosemary has inhibitory effects on S. mutans. They concluded that rosemary was effective on the remineralization process of enamel with high remineralization on fluorescence and microhardness assessments. ${ }^{[27]}$

Commercially available as: SLS and Fluoride Free.

\section{Self-assembling Peptides}

Self-assembling peptide is capable of promoting hydroxyapatite crystal nucleation and supports mineral 
crystal growth in the process of biomimetic mineralization. It is able to regenerate the enamel matrix during enamel formation. Lata and Varghese et al. in 2010 have shown that self-assembling peptide Pl1-4 exhibited a significant difference in remineralizing enamel lesions, triggers that mimic the enamel matrix. Around this matrix, enamel crystals are formed from calcium phosphate from the saliva. ${ }^{[28]}$

Commercially available as: Curodont Repair@).

\section{Remineralization using lontophoresis}

The term iontophoresis is simply defined as ion transfer (ionto $=$ ion; phoresis $=$ transfer $)$. It is a non-invasive method of propelling high concentrations of charged substances. Due to an application of current iontophoresis technique, remineralization takes place at a faster rate in the incipient lesion as the main mechanism of action of fluoride is by the formation of calcium fluoride $\left(\mathrm{CaF}_{2}\right)$ layer on the tooth surface which acts as a fluoride reservoir. Lata $\mathrm{S}$, et al. (2010) in 2017 had done a study to evaluate the efficacy of two different commercially available agents and acidulated sodium fluoride $(\mathrm{NaF})$ gel $0.33 \%$ with or without the iontophoretic procedure for promoting remineralization and they had concluded that $0.33 \%$ acidulated $\mathrm{NaF}$ with iontophoresis has shown better efficacy at the end of 1 month by enhancing remineralization. ${ }^{[29-32]}$

\section{Remineralization using Lasers}

The use of lasers in caries prevention was first suggested in 1972 using a ruby laser. Malik et al., in 2015, have suggested laser irradiation can effectively improve the acid resistance by changing enamel crystals which can prevent the spread and progress of the carious lesion using the antibacterial property of the Er: YAG laser, decontaminate the affected layer that retains its remineralizing potential. Malik A et al. (2015), have shown that Nd: YAG laser irradiation and combined APF treatment of the primary tooth enamel can produce a morphologically hardened enamel surface, which can be a protective barrier against acid attack or even results in less mineral loss compared with the non-irradiated samples. This suggests that Nd: YAG laser could be used for enhancing primary enamel acid resistance. ${ }^{[30-35]}$

Commercially available as: LightWalker AT, Fotona, Slovenia: Er: YAG and Nd: YAG combined laser unit equipped with a comfortable and well-balanced articulated arm (Optoflex, Fotona) and flexible optic fiber.

\section{CONCLUSION}

Demineralization and remineralization are natural processes where mineral content is either lost from or added back into, tooth enamel. Because demineralization makes tooth enamel weaker and more porous, it is associated with the onset of dental caries. The fundamental etiology of dental caries is bacteria, diet and salivary components which result in demineralization of enamel. If demineralization prolongs, excessive loss of minerals leads to loss of enamel structures and eventually cavitation. When $\mathrm{pH}$ rises, the reverse takes place, resulting in deposition of minerals back to the tooth surface. Thus, remineralization is the mechanism through which calcium and phosphate ions are supplied from a source external to the tooth to promote ion deposition into crystal voids in demineralized enamel to produce net mineral gain. Hence, diagnosis of white spot lesions which are early signs of demineralization of tooth due to various etiological factors as described earlier has led a new transaction in preventive dentistry in the form of remineralization using a huge variety of fluoridated and non-fluoridated agents.

\section{REFERENCES}

1. Ana Maria A, Montero M, Rojas-Sanchez F, Machado C, Rivera LE, Wolff M, et al. Clinical evaluation of the ability of cavistat in a mint confection to inhibit the development of dental caries in children. J Clin Dent 2008;19:1-8.

2. Chokshi K, Chokshi A, Sebastian SS, Zaheer A, Dhanya RS. Newer non-fluoridated remineralizing agents: An insight. Int J Oral Care Res 2016;4:291-6.

3. Xu HH, Moreau JL, Sun L, Chow LC. Nanocomposite containing amorphous calcium phosphate nanoparticles for caries inhibition. Dent Mater 2011;27:762-9.

4. Pessan JP, Al-Ibrahim NS, Buzalaf MA, Toumba KJ. Slow-release fluoride devices: A literature review. J Appl Oral Sci 2008;16:238-46.

5. Swarup JS, Rao A. Enamel surface remineralization: Using synthetic nanohydroxyapatite. Contemp Clin Dent 2012;3:433-6.

6. Raghu TN, Ananthakrishna S. Remineralization potential of calcium sucrose phosphate on demineralized enamel: Results of an in vitro study. J Int Oral Health 2016;8:704-8.

7. Li X, Wang J, Joiner A, Chang J. The remineralisation of enamel: A review of the literature. J Dent 2014;42 Suppl 1:S12-20.

8. Stephens KW, Creanor SL, Russell JI, Burchell CK, Huntington E, Downie CF. Fluoride toothpastes, rinses and tablets. Adv Dent Res 1994;8:185-9.

9. Twetman S, Axelsson S, Dahlgren H, Holm AK, Källestål C, Lagerlöf $\mathrm{F}$, et al. Caries-preventive effect of fluoride toothpaste: A systematic review. Acta Odontol Scand 2003;61:347-55.

10. Cury JA, Tenuta LM. Enamel remineralization: Controlling the caries disease or treating early caries lesions? Braz Oral Res 2009;23 Suppl 1:23-30.

11. Soi S, Vinayak V, Singhal A, Roy S. Fluorides and their role in demineralization and remineralization. J Dent Sci Oral Rehabil 2013;4:7-10.

12. Savice KJ. Caries risk assessment. Op Dentn 2001;6:19-26.

13. Murray JJ, Rugg-Gunn AJ, Jenkins GN. A history of water fluoridation. In: Fluorides in Caries Prevention. $3^{\text {rd }}$ ed. Oxford: Wright; 1991.

14. Dhull KS, Nandlal B. Effect of low-concentration daily topical fluoride application on fluoride release of giomer and compomer: An in vitro study. J Indian Soc Pedod Prev Dent 2011;29:39-45.

15. Tiwari S, Nandlal B. Comparative evaluation of fluoride release from hydroxyapatite incorporated and conventional glass ionomer cement: An in vitro study. J Indian Soc Pedod Prev Dent 2012;30:284-7.

16. Shirahatti RV, Ankola AV, Nagesh L, Hallikerimath S. The effects of 
three different pastes on enamel caries formation and lesion depth progression - An in vitro study. J Oral Health Comm Dent 2007;1:1-6.

17. Gjorgievska ES, Nicholson JW. A preliminary study of enamel remineralization by dentifrices based on recalden (CPP-ACP) and novamin (calcium-sodium-phosphosilicate). Acta Odontol Latinoam 2010;23:234-9.

18. Karlinsey RL, Mackey Ac. Solid state preparation and dental application of an organically modified calcium phosphate. J Material Sci 2009;44:346-9.

19. Sullivan RJ, Masters J, Cantore R, Roberson A, Petrou I, Stranick M, et al. Development of an enhanced anticaries efficacy dual component dentifrice containing sodium fluoride and dicalcium phosphate dihydrate. Am J Dent 2001;14 Spec No:3A-11A.

20. Heshmat H, Ganjkar MH, Jaberi S, Fard MJ. The effect of remin pro and MI paste plus on bleached enamel surface roughness. J Dent (Tehran) 2014;11:131-6.

21. Rees J, Loyn T, Chadwick B. Pronamel and tooth mousse: An initial assessment of erosion prevention in vitro. J Dent 2007;35:355-7.

22. Pratiwi AR, Meidyawati R, Djauharie N. The effect of MTA application on the affected dentine remineralization after partial caries excavation (in vivo). J Phys Conf Ser 2017;884:012119.

23. Ritter AV, Bader JD, Leo MC, Preisser JS, Shugars DA, Vollmer WM, et al. Tooth-surface-specific effects of xylitol: Randomized trial results. J Dent Res 2013;92:512-7.

24. Firestone AR, Schmid R, Mühlemann HR. Cariogenic effects of cooked wheat starch alone or with sucrose and frequency controlled feedings in rats. Arch Oral Biol 1982;27:759-63.

25. Szoke J, Banoczy J, Proskin HM. Effect of after meal sucrose free chewing gum on clinical caries. J Dent Res 2001;80:1725-9.

26. Khaddam M, Salmon B, Le Denmat D, Tjaderhane L, Menashi S, Chaussain C, et al. Grape seed extracts inhibit dentin matrix degradation by MMP-3. Front Physiol 2014;5:425.

27. Al-Duboni G, Muhamed T, Al-Naggar RA. Antimicrobial activity of aqueous extracts of cinnamon and ginger on two oral pathogens causing dental caries research. J Pharm Biol Chem Sci 2013;4:957-65.

28. Dalirsani Z, Aghazadeh M, Adibpour M, Amirchaghmaghi M, Pakfetrat A. In vitro comparison of the antibacterial activity of ten herbal extracts against Streptococcus mutans with chlorhexidine. J Appl Sci 2011;11:878-82.

29. Lata S, Varghese NO, Varughese JM. Remineralization potential of fluoride and amorphous calcium phosphate-casein phosphopeptide on enamel lesions. J Conserv Dent 2010;13:42-6.

30. Malik A, Parmar G, Bansal P, Joshi N. Effect of laser and fluoride application for prevention of dental caries. A polarized microscope analysis. J Dent Lasers 2015;9:11-5.

31. Castellan CS, Luiz AC, Bezinelli LM, Lopes RM, Mendes FM, De PE, et al. In vitro evaluation of enamel demineralization after Er: YAG and Nd: YAG laser irradiation on primary teeth. Photomed Laser Surg 2007;25:85-90.

32. Sharafeddin F, Mehran M, Modiri S. Effect of immediate application of pomegranate peel, grape seed extract and green tea extract on remineralization of enamel. Res J Biol Sci 2013;8:83-7.

33. Kind L, Stevanovic S, Wuttig S, Wimberger S, Hofer J, Müller B, et al. Biomimetic remineralization of carious lesions by self-assembling peptide. J Dent Res 2017;96:790-7.

34. Kanishk G, Vani T, Kumar S, Bhat S. Remineralizing agents-an insight into the current and future trends. Int J Oral Health Med Res 2016;3:55-8.

35. Bharti M, Nagar P, Aminah M, Singh P. Effect of laser and fluoride application for remineralization of the carious lesion: A polarized microscopic study. Int J Contemp Med Res 2017;4:489-92..

How to cite this article: Saini J, Gupta A, Srivastava A, Kataria S. Agents to Maintain Tooth Integrity: An Equilibrium between Remineralization and Demineralization - A Review Article. Int J Dent Med Spec 2019;6(1):9-14.

Source of Support: None; Conflict of Interest: None 